\title{
DESIGNING A MOBILE-BASED LEARNING MEDIA EDUCATIONAL GAME APPLICATIONS
}

\author{
Alvino Octaviano ${ }^{1}$, Achmad Udin Zailani ${ }^{2}$, Shandi Noris ${ }^{3}$, Hadi Zakaria ${ }^{4}$, Samsoni ${ }^{5}$, \\ Cahyo Putro Prakoso ${ }^{6}$ \\ 1,2,3,4,5 Lecturers, Department of Informatics Engineering, University of Pamulang, Banten, Indonesia \\ ${ }^{6}$ College Students, Department of Informatics Engineering, University of Pamulang, Banten, \\ Indonesia \\ E-Mail: dosen00397@unpam.ac.id
}

\begin{abstract}
The smart phone is one part of technological developments that have been to a basic human need. Android is an operating system with an open platform. Current technological developments and needs can be made practical and attractive on Android-based phones, one of which is education. Systems development method in this study, using a design of this mobile-based educational game learning media application, i.e., a linear sequential model or often referred to as the waterfall model. This educational game is expected to facilitate student learning by way of delivery packaged as attractive as possible to stimulate feelings of pleasure in students so that it is easy to understand the material presented.
\end{abstract}

Keywords: smart phone, educational game, android

\section{INTRODUCTION}

Human life is facilitated with the aid of technology to answer the human needs increasingly varied in daily activity. The thrive of online media is an opportunity for the information society [1]. Business people must pay concern to develop an interactive system, which in the atmosphere use of information in social change [2]. This condition is also added to human life with a cling utilized of smart phones.

Smart phones are one part of technological developments that have to adhere to a basic human need. Android is an operating system with an open platform [3]. Current technological developments and needs can be made practical and attractive on Android-based phones, one of which is in the world of education, such as educational [4].

Every child today who is a student must have used a smart phone; most of them use it to play games. They argue that games can be used as a tool for refreshing when bored with learning. But in fact they play more games that are not useful to increase their knowledge and instead become addictive, so they forget the time to study. The image of games in society is still seen as an entertaining medium compared to learning media. Even in some people's bad view, they see the many cases of children addicted to games.

Many people don't know about educational games because of the lack of educational games compared to other games, even though this educational type game aims to provoke children's interest in learning subject matter while playing. [5]. Learning methods in schools are starting to be considered unattractive and even monotonous. Because the method of delivering the material seems like that and only uses the book method. Other expectations betwixt students for supposed to learn from a lecture and how students should engage in the lecture to understand this content, such as fuzzy conjoint model [6]. For elementary school students who still like to play. The use of educational game learning media is still relatively rare, the reality in this field encourages writers to develop educational games based on Android [7]. This educational game application is made using the Waterfall method, whose stages are so detailed that it makes it easier for the writer.

This educational game application will later contain explanations of material in the form of animations, games, and multiple-choice quizzes, which can also be used as an evaluation of the learning system to anticipate limited learning time in class [4]. In teaching can generate new desires and interests. Generating communication and stimulation of learning activities and even having a psychological influence on students. Utilizing technological developments for the success of a learning process so that learning activities are more interesting and not monotonous only uses book media [8].

Systems development method in this study, using a design of this mobile-based educational game learning media application, i.e., a linear sequential model or often referred to as the waterfall model [9]. This stage follows as:

a. Planning; at this stage, the application to be made is planned as carefully as possible by considering everything. From the start of the manufacturing stage to the possibility of failure, everything is planned at this stage.

b. Analysis; at this stage, the application is analyzed according to what has been planned; if there are still deficiencies, it will be corrected at this stage.

c. Design; at this stage, the display of the system is designed as well and as attractive as possible to make users like the application that has been designed.

d. Implementation; at this stage, the system is implemented thoroughly before being given to users. Is this application really worth giving to its users? If there are still shortcomings, this application refined again [10]. 


\section{LABORATORY TESTS, RESULTS AND} ANALYSIS

System Analysis

System analysis defined as the decomposition of a complete information system into parts of its components to identify and evaluate problems, opportunities, obstacles that occur, and the expected needs so that they can be. Before the design stage of a system is carried out, it is necessary to analyze the system to be built. Systems analysis is a term that collectively describes the early phases of system development. This stage aims to provide a clear picture of the system to be built. This stage describes the requirements useful for system design so that the system is built following the problem to be resolved [11]. Analysis of system requirements are some of the material requirements in the system that used to add and help make an object. This section will be divided into two parts.

Analysis of functional requirements contains what processes will be carried out by the system. Functional requirements also contain what information the system must have and produce:

- Displaying subject matter in animated form

- Displays multiple-choice quizzes to hone and evaluate the material that has been presented

- Games, which serve as a medium of relaxation

Non-functional requirements analysis is a requirement type that contains properties owned by the system. This requirement is divided into two parts:

- Device Requirements; the hardware used in this study are Laptop, Monitor, Keyboard, Mouse, and Smartphone

- Software Requirements; the software used in this research are Windows 10 (64 bit) Operating System, Adobe Photoshop CC 2019, and Construct Release 175 (64 bit)

\section{Application Design}

Application design is the next stage after system analysis gets a clear picture of what is being done. Then proceed with thinking about how to form the system. In designing this system using UML (Unified Modeling Language), it includes case diagrams, activity diagrams, sequence diagrams. In designing this application, there is also a user interface (interface), which is the first step in making Mobile-Based Learning Media Educational Game Application Design's appearance.

General description of the proposed system to provide a general description of the user regarding the mobile-based application system. System design, in general, can also be done regarding system components so that the direction of system design is directed at the target; therefore, the system design must meet the system limitations where the design of this application system is a functional requirement. Implementation describes how a system is formed. At the design stage, the mobile application is designed to communicate between the user and the program maker to get an application system per what is needed. Use case diagrams to explain what the system and actors will do concerning the processes in the system. In designing the use case diagram, this will explain the things that users can do [12]

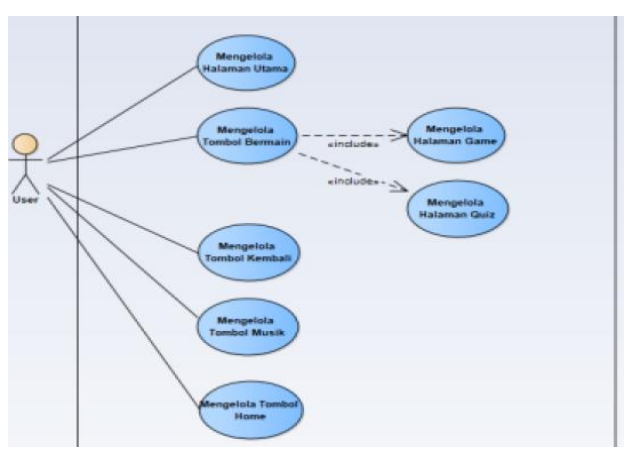

Fig. 1. Use Case Diagram

In Figure 1 in this application, students can do several things like in the use-case above, with the following explanation:

a. Managing the Main Page

On this page, the user will shown the main menu of the Mobile-Based Learning Media Educational Game Application Design. On this main page will be presented several buttons, namely the button: Play and Music.

b. Manage Play Buttons

On the Play button menu, the user will be presented with the Play button, namely Play. After the play button is pressed, the user will be presented with the GreenVBox game. This game aims to be used as a medium for children's relaxation to not feel bored because of continuous learning. Then after the user has successfully passed the hurdle, the user is invited to a quiz page. This quiz aims to be used as a medium for evaluating learning from the material that has been read. This quiz is packaged as attractive as possible to attract students' interest in doing the evaluation.

c. Back

On the back button, the user can return to the previous page.

d. Music

Turn off or turn on the music in the game. However, the only music that is turned off is the music on the main page. For music from the material narration, be turned off.

e. Exit

This button is used to exit the Mobile-Based Learning Media Educational Game Application. However, users can also exit this application by using the back or home button on the smart phone used.

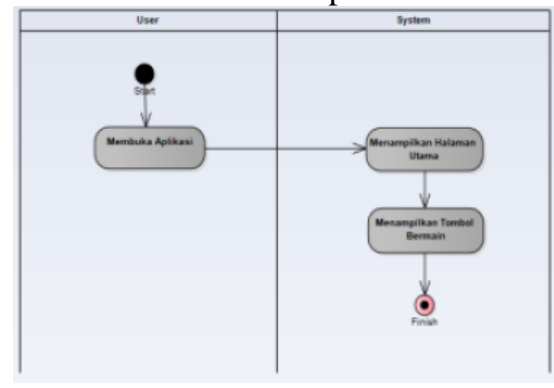

Fig. 2. Main Page Activity Diagram

Figure 2 is an activity diagram from the system's main page, which illustrates the main display when the user opens the Educational Game Application for Mobile-Based 
Learning Media.

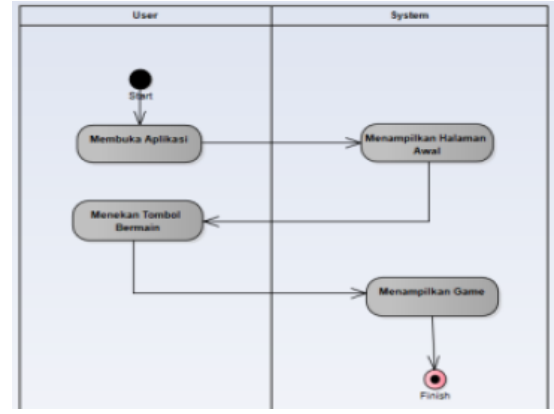

Fig. 3. Play Button Activity Diagram

Figure 3 is an activity diagram of the play button in the system, which illustrates the initial appearance when the user opens the play menu button.

Sequence diagrams describe objects that participate in a use case and the messages contained between them from time to time for a use case; sequence diagrams are also used to model descriptions of the existing system in one or several use cases in the use case diagram, which describes the relationship between actors and use cases. The following is a sequence diagram contained in the Design of Educational Game Applications for Mobile-Based Learning Media.

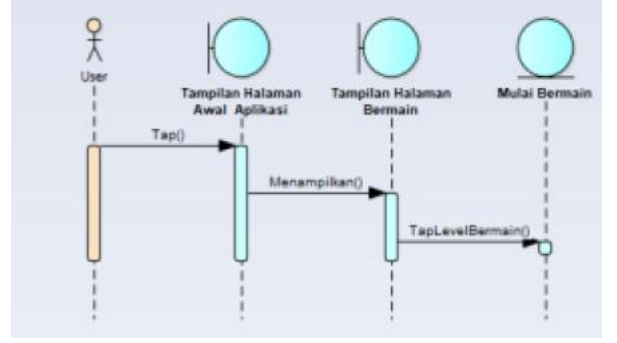

Fig. 4. Starting Sequence Diagram

In Figure 4, the start sequence diagram shows that when the user opens the Educational Game Application for Mobile-Based Learning Media, the system will respond by displaying the main page of the application. Then, on this main page, the system has two buttons, namely the play button and the music button. After the user presses the play button, the user will be directed to the quiz page, where the user can then complete the quiz to go to the next.

\section{Implementation}

The implementation stage is carried out after the analysis and design process has been completed, which will then be implemented into the programming language. Then after implementation, it tested on this application. Applications that have been built will be implemented to determine whether the system can run according to its purpose or not [13].

The purpose of implementation is to apply the design and develop the system that has been created. The Design of Educational Game Applications for Mobile-Based Learning Media ran in the operating system and hardware; the implementation and testing stages will be fully carried out on hardware with the Windows 10 operating system using Construct 2 software and carried out on the system as a simulation process of the Design of Educational Game Applications Mobile Based Learning Media. a. Hardware and Software Specifications

In making the Design of Educational Game Applications for Mobile-Based Learning Media, namely using hardware and software that communicate with each other to allow a new process. The process to occur where one of them is the process of making this application. The implementation and testing stages are carried out entirely on hardware and software with detailed specifications as follows:

- Hardware are the components that build a computer or laptop that can help to create an application that is designed and makes it easier to do it and in processing the information needed. Hardware is also required to run this application.

- Software is a special term for data that is digitally formatted and stored, including computer programs, their documentation, and various information that can be read and written by a computer. Software is also required to support this application.

b. Interface Implementation

The implementation of the interface or user describes the application's appearance, namely the Design of Educational Game Applications for Mobile-Based Learning Media. The interface implementation uses the results from the screen capture for each menu in this application. And the following is implementing the interface or user interface in the Design of Educational Games for Mobile-Based Learning Media.

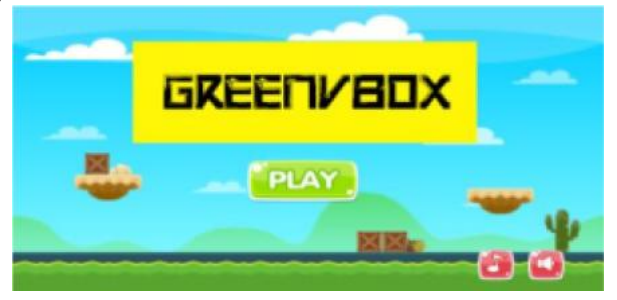

Fig. 5. Main Menu Display

In Figure 5 above, on the main menu display of Educational Game Application Design for Mobile-Based Learning Media, there are three buttons: the play button, the music button, and the sound button. The play button functions to start the game, and the music button, along with the sound button, functions to issue and deactivate sounds to make the game less likely to get bored. The main menu display has a cheerful background, which is expected to attract users to play this game.

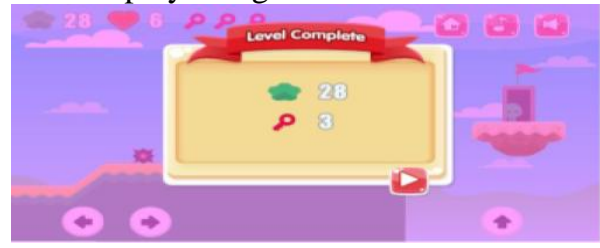

Fig. 6. Next Level Display

In Figure 6, after the user has successfully passed the obstacles at each level, the game will display a MobileBased Learning Media Educational Game Application Design menu; this menu also displays the acquisition of gems and remaining hearts while the game is running. The red triangle button above functions to open the next level. 


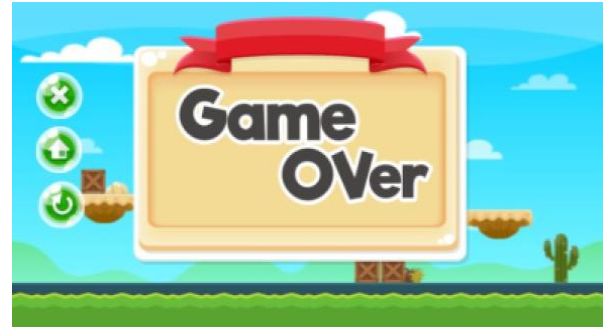

Fig. 7. Game Over Page Views

In Figure 7, if the GreenVBox actor is hit by a spiked enemy ball or an enemy flying 3 times, then the user's heart will decrease. The heart is given only 3 times if the user continues to be hit by enemy spikes or flying enemies 3 times, then the automatic game over, and the user will brought to the page as above. The reload button serves to replay the game back to the play page.

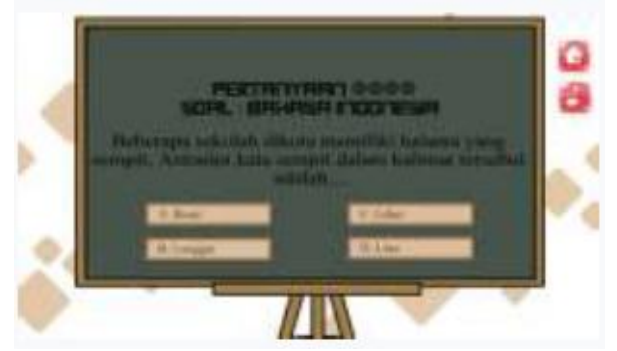

Fig. 8. Display of Indonesian Quiz

Figure 8 shows the contents of the Quiz menu. This page displays several multiple-choice questions with material from different subjects such as Social Sciences, English, Mathematics, and Indonesian. This question must answer until it is correct, if the answer is still wrong, then the game will be game over, and the user must return to playing and meet the same question until he chooses the correct answer to continue to the next level.

\section{CONCLUSIONS}

After analyzing and designing problem-solving solutions and implementing the system was built, it can be concluded as follows: (1) With the Mobile-based Learning Media Educational Game Application, children's interest in studying subjects can be achieved because the packaging of the material is not boring, and (2) With the Educational Game Application for Mobile-based learning media, the people's perspective on games has begun to change into a positive view because if used properly, games will become a medium that really helps learners' learning.

\section{REFERENCES}

[1] Sri Lestari Rahayu, Fujiati , and Rofiqoh Dewi, "Educational Games as A learning media of Character Education by Using Multimedia Development Life Cycle (MDLC)," in The 6th International Conference on Cyber and IT Service Management (CITSM 2018), Parapat, Indonesia, 2018.

[2] T. Husain, Asrul Sani, Maulana Ardhiansyah, and Ninuk Wiliani, "Online Shop as an interactive media information society based on search engine optimization (SEO)," International Journal of Computer Trends and Technology, vol. 68 , no. 3, pp. 53-57, March 2020.

[3] Martin Kenney and Bryan Pon, "Structuring the Smartphone Industry: Is the Mobile Internet OS Platform the Key?," Journal of Industry, Competition and Trade, vol. 11, pp. 239261, June 2011.
[4] Abdur Razzaq, Yulia Tri Samiha, and Muhammad Anshari, "Smartphone Habits and Behaviors in Supporting Students Self-Efficacy," International Journal of Emerging Technologies in Learning (iJET), vol. 13, no. 02, pp. 94-109, 2018.

[5] Zirawaga, Victor Samuel, Olusanya, and Adeleye Idowu, "Gaming in Education: Using Games as a Support Tool to Teach History," Journal of Education and Practice, vol. 8, no. 15 , pp. 55-64, 2017.

[6] N. Sarala and R. Kavitha, "Fuzzy Conjoint Model in Measuring Students' Expectation and Teachers' Beliefs on Learning Mathematics," International Journal of Advanced Trends in Engineering, Science and Technology, vol. 2, no. 2, pp. 6-10, Marct 2017.

[7] Bertaria Sohnata Hutauruk, "English for Spesific Purposes," FKIP, Pematangsiantar, Teaching Module 2015.

[8] Talizaro Tafonao, Setinawati, and Ezra Tari, "The Role of Teachers in Utilizing Learning Media as A Learning Source for Millenial Students," in Proceedings of the 1st Asian Conference on Humanities, Industry, and Technology for Society, ACHITS 2019, 30-31 July 2019, Surabaya, 2019.

[9] Rick Sherman, "Business Intelligence Guidebook: From Data Integration to Analytics," in Project Management.: Elsevier Inc., 2015, ch. 18, pp. 449-492.

[10] Andri Suryadi, "Perancangan Aplikasi Game Edukasi Menggunakan Model Waterfall," Jurnal PETIK, vol. 3, no. 1, pp. 8-13, March 2017.

[11] John W. Satzinger, Robert B. Jackson, and Stephen D. Bur, Systems Analysis and Design in a Changing World, 7th ed. Boston: Course Technology, Cengage Learning, 2015.

[12] Marchese/CS389, "Use Case Diagrams," Seidenberg School of CSIS, New York.

[13] Adrienne Watt, "Software Development Life Cycle Waterfall," in Database Development Process, 2nd ed.: Pressbooks, 2014. 